\title{
Learning Computing Heritage through Gaming - whilst teaching digital development through history
}

\author{
Jim Wood \\ University of Bedfordshire \\ University Square, Luton LU1 3JU, UK \\ jim.wood@beds.ac.uk
}

\author{
Haiming Liu \\ University of Bedfordshire \\ University Square, Luton LU1 3JU, UK \\ haiming.liu@beds.ac.uk
}

\author{
Thomas Briggs \\ Bletchley Park Trust Museum \\ Bletchley Park, MK3 6EB, UK \\ tbriggs@bletchleypark.org.uk
}

\begin{abstract}
This paper analyses the potential of computer games and interactive projects within the learning programmes for cultural heritage institutions through our experiences working in partnership between higher education and a museum. Gamification is cited as a key disruptive technology for the business and enterprise community, and developments in games technology are also driving the expansion of digital media into all different screen spaces, and various platforms. Our research aims to take these as beneficial indicators for pedagogic development, using gaming to support knowledge transfer related to a museum setting, and using the museum as a key scenario for our students to support the practice of game development. Thus gamification is applied as both a topic and a methodology for educational purposes.
\end{abstract}

Gamification. Interactive experiences. Digital technologies. Museums. Teaching and learning

\section{INTRODUCTION}

The inspiration for this project came from a meeting between members of the Department of Computer Science at University of Bedfordshire (2016) and the Education Team at Bletchley Park Trust. Bletchley Park (2016) is known as "the home of the codebreakers" including the key work during World War II by now recognised figures such as Alan Turing and Gordon Welchman among others. As a key heritage site in the history of the development of computing, and a local institutional partner there was a natural fit between the two parties. Demonstrating the potential for games and interactive technologies to be used in the museum education context a relationship was made. During a pilot partnership project between our University Department and the Museum's Education team, prototypes such as a web-based game and other interactive projects were created from briefs given by the Education officers to demonstrate the potential for enhancing the learning of school-age groups through curriculum relevant topics such as codes, ciphers and cryptography through digital technology. This also provided the dual role of giving a 'live brief' and active scenario to encourage professional practice within the students who developed the projects.

This paper discusses the experience of a university academic team working with a museum education team to promote the use of games and interactive technologies for students learning experiences, within the context of the museum education programme.

To introduce the museum, Bletchley Park is the now well known, but at the time secret, base for the Government Code and Cypher School (GC\&CS) a predecessor to the current Government Communications Headquarters (GCHQ), that was situated in this mansion and estate at Bletchley, Buckinghamshire, during the Second World War era. Since the late 1990s acting as a heritage visitor attraction, the site is now an active museum that has benefited from a series of re-developments of the former military-style Huts and Blocks into exhibition and archive spaces, culminating in the major eight-million pound renovation of Block $C$ as a visitor centre fit for a contemporary museum experience opened in June 2014.

Visitor numbers to the site have grown rapidly in recent years - from 40,000 in 2006 to 150,000 in 2012 (Bletchley Park 2016b) and reaching 286,000 in 2015 (ibid.). As a result it is necessary to engage with a greater number of visitors on an educational level, and it is imperative that we research new ways of doing this, both on-site and remotely. As well as reaching more people we also want to embrace the diversity of society and introduce people from a wider range of interests, backgrounds and skillsets to the story of Bletchley Park. 
The education department at Bletchley Park hosts a popular on and off-site formal learning programme, and is working to extend its informal offering to general site visitors. In all of these areas we are committed to updating and improving what we do, and we are enthusiastic about the opportunities and inspiration provided by new and emerging interactive technologies that may help us to achieve this aim.

From the Higher Education academic perspective the motivation from this project came from our previous experience of working both on museumrelated projects and our teaching curriculum in games development and interactive media design. As part of a previous teaching and learning project (Liu \& Wood 2013) supported by the University we initiated a research into the use of 'live briefs' or client interaction in this context. Though common in Art and Design or Media department courses, these kinds of relationships were not typical in the Computing department where we are lecturing. However there is an incentive to link teaching, particularly in practical subjects involving design and digital artefacts with real-world examples, or what is known as 'Industry Focused'. It has been our observation also that in most cases the sense of interaction with professionals outside the University environment increases engagement with project work, and can lead to positive outcomes.

Thus after initial meetings a series of visits have taken place between the authors with groups of students who have taken briefings from the museum for the topic of assignments or projects that they have carried out as part of their studies. This will be explained in further detail in section 3 .

\section{BACKGROUND RESEARCH}

The first part of this section is dedicated to related research and literature on the topic of gamification and interactive technologies for museums.

\subsection{Related Literature}

In terms of Gamification we cite research in this area that helps to give an understanding of the term, and how it may be applied in this context. In fact it seems necessary to set the scope more clearly by referencing two sub-terms from related literature; 'gameful' and 'gamifying'.

In From Game Design Elements to Gamefulness: Defining "Gamification" Deterding et al. (2011) seek to find an updated definition for "gamification" by contrasting various previous examples noting that: "Current industry uses of the term fluctuate between two related concepts. The first is the increasing adoption, institutionalization and ubiquity of (video) games in everyday life. The second, more specific notion is that since video games are designed with the primary purpose of entertainment....game elements should be able to make other, non-game products and services more enjoyable and engaging as well." (Deterding et. al. 2011).Considering our approach to using games and the teaching of games-related design for a museum context, that the second definition here has a more direct combination. In starting the project it had been our intention that adding elements of gaming and interaction to the museum context would enable other levels of engagement in the area where video games are not usually found. This definition was useful in developing the research topic and was later explored in the usercentred research that was carried out in developing the prototype projects.

Further analysing terms such as 'playful', the use of play within different contexts and the newer term 'gameful' Deterding et al. (2011) develop the view that gamification:

\begin{abstract}
"...does indeed demarcate a distinct but previously unspecified group of phenomena, namely the complex of gamefulness, gameful interaction, and gameful design, which are different from the more established concepts of playfulness, playful interaction, or design for playfulness. Based on this observation, we propose the following definition: "Gamification" is the use of game design elements in non-game contexts."
\end{abstract}

Therefore in the context that we aimed for to our student's projects, the scenario of the museum is non-typical for game design. But as the students navigate the learning and development process of constructing their computer game artefacts both in technical and creative aspects, there is a benefit in bringing their experience of gaming and its mechanisms off the screen and into the heritage context.

Furthermore the use of games in specific settings such as museums that have a link to the Science, Technology, Engineering, and Mathematics (STEM) curriculum is more common. A second example study analyses the role of games \& gamification within the 'science centre' (Bergström et al. 2014). Visitor centres and museums of science such as the Science Museum, London (2016), or children's museums such as Eureka! (2016) are noted as being institutions that had lead the way, and previously pushed the boundaries of visitor interaction. In the UK, this has been apparent since the 1980s with the inclusion of specialised adventurous child friendly activities such as the original 'Launchpad' exhibit at the Science Museum, London (Stevenson 1987).Since that time the use of mechanical and tangible 
displays has proliferated, and it now common to think of science centres and museums within these categories. It may even have influenced the way science and the STEM subjects have been taught within the school curriculum and certainly within the presentation on television, with popular shows such as 'Bang Goes the Theory' (BBC 2016).Studying a contemporary example 'Tom Tits Experiment' (Bergström et al. 2014) that heavily features active and engaging exhibits, the research focuses on those that include tangible and physical interaction and are designed to encourage the type of "explorative learning" that is common in tangiblebased interaction as part of $\mathrm{HCl}$ research (Marshall 2007).

Developing from this Bergström et. al. focus on a research project to 'gamify' the science centre as a whole - this includes setting up a framework for an overarching game (play) that could link together different exhibits and increase the interaction between groups of visitors, and especially the children and adults, rather than their observation of adults watching children's play. In doing this they create ways of scoring and building up a profile using identification technologies -Radio Frequency Identification RFID, Quick Response (QR) codes, and add more user-based interaction to compliment the physical exhibits.

In summary, the cited case studies point out how the "major reasons ... were to increase attractiveness to a computer-game fed generation; increase opportunities for family engagement..." (Bergström et. al. 2014) This fits well with the initial motivations of this project at Bletchley. Also, as will be seen in the more extensive user-experience research carried out by our second example project, the point of engaging with a computergame generation is a key question, when it is considered if the current interactive exhibits though relatively new - are engaging with this younger gaming audience? Including a usercentred research and design phase as part of project development as will be explained in section 3.2 has the potential to identify these issues.

\section{EXAMPLE GAME PROTOTYPES}

In this section a selection of game prototype examples are shown, made by student teams or individual students that have participated in the project. These include first a web-based game that goes from an initial 'interactive' version, to a more developed 'gameful' version. Followed by a second selection of early designs for tangible interactive prototypes that take the gamification of the museum's stories into novel objects that are designed to promote a literal hands-on approach to learning through gaming.

\subsection{Web-based}

This first project that emerged following initiation of the relationship between the academic team and the Bletchley education team, takes the scenario of a web-based learning game designed to support the curriculum of the aforementioned learning programme. This was based on learning material on code-breaking, ciphers and the background historical narrative of the museums story - related to breaking the Enigma code. The first student team visiting the Museum and park did research for this. The audience for this was described as the typical younger children (KS1\& KS2) who visit the education department of the museum in groups as part of school visits, and also a general audience who are interested in rediscovering the historical aspects of the site. (Bletchley Park 2016c) It also was noted that many of the visitors to Bletchley Park are older or retired people who may be attracted given their own history of growing up in the post-war era in the shadow of WWII and maintain an interest in it, though not the target learners they may also be the general audience.

Therefore the design of the initial web-based game was based on explicating some of these initial objectives: giving background information to the history of the site, and demonstrating a series of simple (but increasingly complex) code cyphers.

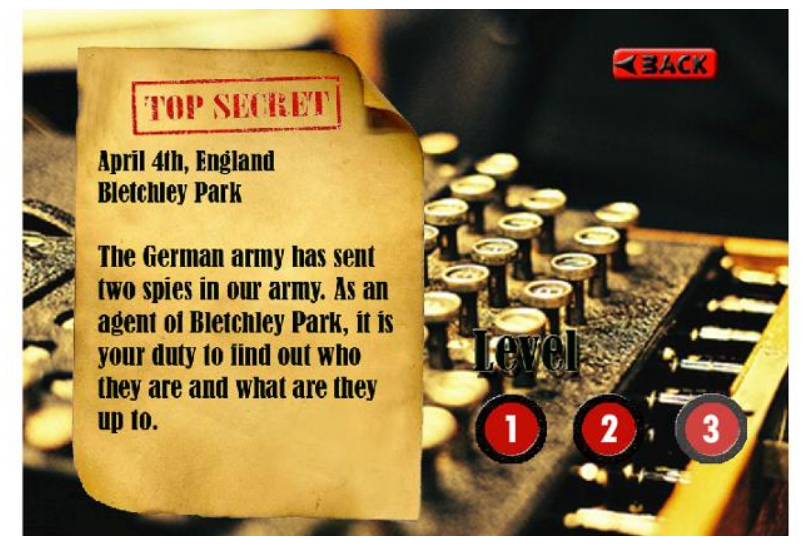

Figure 1: Web-based game, 1st prototype - Introduction screen (Student Group A)

The presentation of this first prototype was adequate as part of the students' learning experience, but after the end of the semester the development the ceased, a common problem when negotiating task with student groups. However the prototype was used as an example for showing the potential of the relationship.

Recently a second team has taken on the development of the project and developed new features including more gameful features, such as challenges, clues and repeating tasks. In continuing the development, this more experienced 
team (Student Group B) have iterated the design based on further feedback given by the teaching team and the museum team. Being able to meet on a number of occasions helped to guide the progress. Figure 3 (below) shows a $3^{\text {rd }}$ level screen that was originated by this team based on the story of the one bombing incident that happen at Bletchley during the WWII period. Although thought to be an accidental hit by the Luftwaffe, the story is dramatized here through a decoding and finding task.

In summary, this section has shown an example of the kind of web-based game that has been developed from students' projects and that represent a gamified version of a learning resource that addresses some of the key learning objectives of the KS1 material.

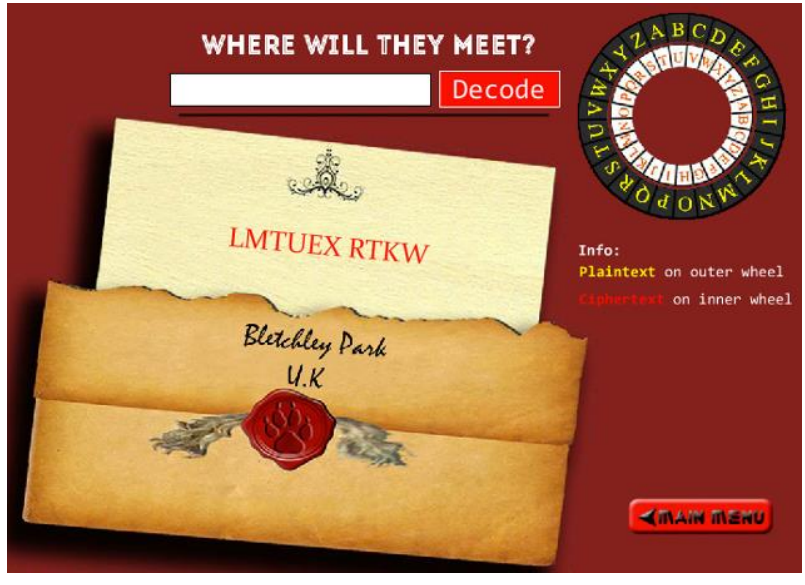

Figure 2: Web-based game, 1st prototype-2nd level screen (Student Group A)

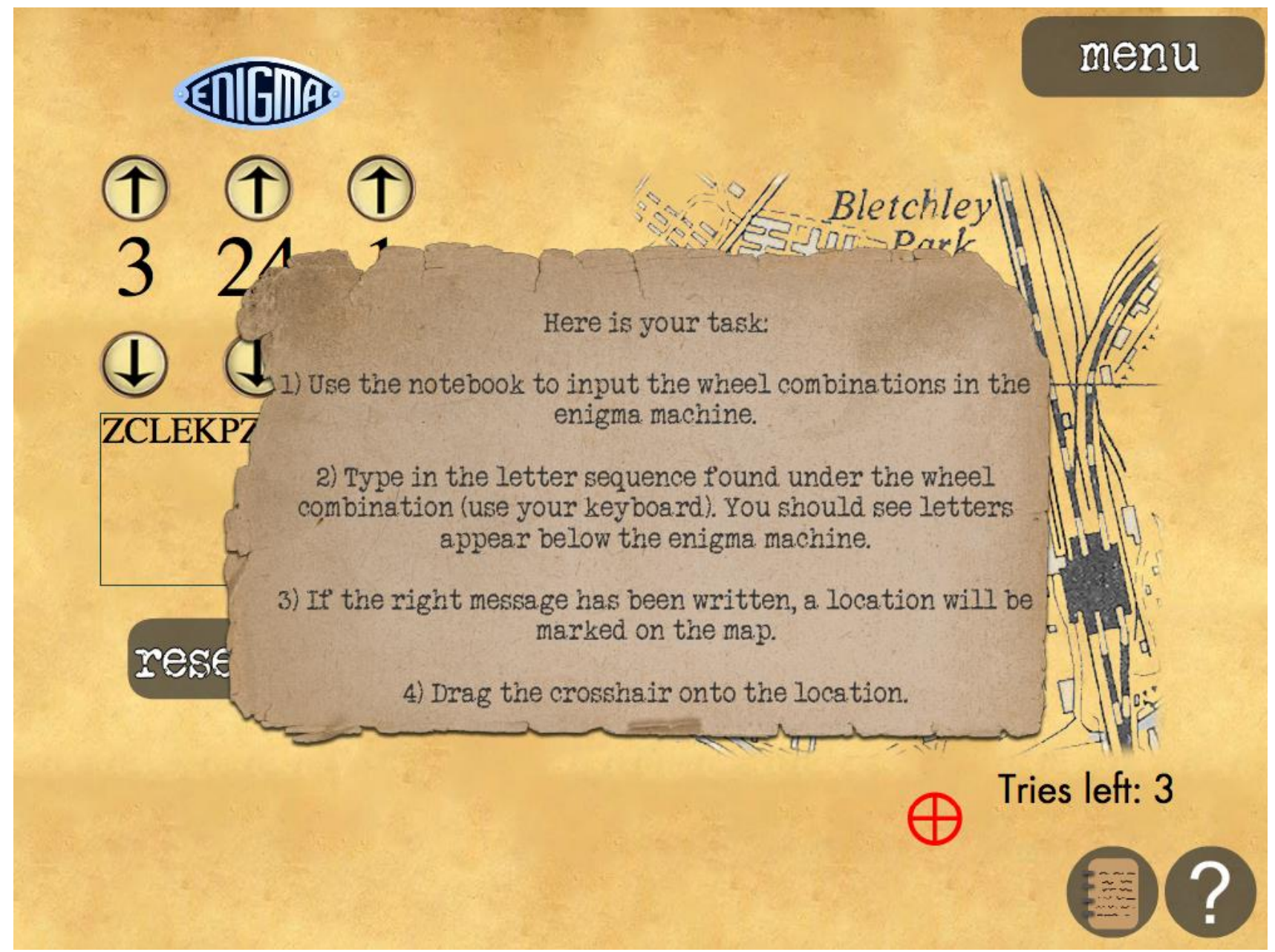

Figure 3: Web-based game, $2^{\text {nd }}$ prototype version - Level 3 screen (Student Group B)

\subsection{Interactive Objects}

For a more recent teaching project brief we applied the story and context of Bletchley Park museum to an extended curriculum for the technology of interactive objects. The initial aims of this module were to introduce interactive prototyping for objects, rather than for screen-based design as done in the web-based games and other modules in the curriculum. So that whilst games and gamification based on typical video games scenarios are quite typical, extending the concept of gamifying to physical objects with embedded interactive components is more complex, but has more wide ranging potential. 
This was explained in the briefing by reference to a recent concept, Enchanted Objects originated by David Rose (2014). Related to the much written about Internet of Things (IOT) concept and its relationship to Ubiquitous Computing (Uckelmann et. al. 2011) but has a more poetic design and narrative approach to future interactive objects that focuses on human experience and desire. Example objects such as the Ambient Umbrella and the Nabaztag Rabbit are everyday products that are enhanced by digital technology for network connectivity or data visualisation, but are not smart devices with embedded touch screens. They are exemplified by a ranking of desires such as telepathy, safekeeping or teleportation rather than a technical protocol or specification (Rose 2014).

In introducing the project briefing to the student group, it was noted that there is a clear relationship between the use of interactive devices and contemporary museum interactives. As noted earlier, use of digitally-enhanced interactive displays dates back at least to the original Launchpad installations at the London Science Museum, and is now commonplace in museum exhibition design (Keene 2014). The more recently opened exhibitions in Bletchley Park's 'Block C' include video and interactive displays that support the recreation ('sets/stages?) of scenes, such as the offices of code breakers and communications staff. (Event Communications 2016, DJ Willrich 2016) These professionally designed and made interactives are largely screen-based video vignettes featuring actors filmed portraying silent characters. There are also touch screen displays, which are largely informative, and have some games included. However, similarly to the case study in the research above (Bergström et. al. 2014), they do not feature any overarching gameplay or link between them. This may have been a curatorial decision in this case, but for our teaching project it gave us a space to interpret the topic with a different approach. Rather than trying to compete with these large-scale displays a focus was given on the everyday objects that represented the era, and how they could be enchanted with interactive technologies and be part of gameplay scenarios.

Following an early visit to the museum by this group, students were first asked to some concept boards using digital images, and then to explore interactivity using and software. The aim is to consider the scenario for the interactive objects, and relate the idea to the historic context of the site. Thus vintage objects from the era were selected as potential candidates for enchantment, and software examples were shown to imagine how these could be made interactive. (Figure 4)

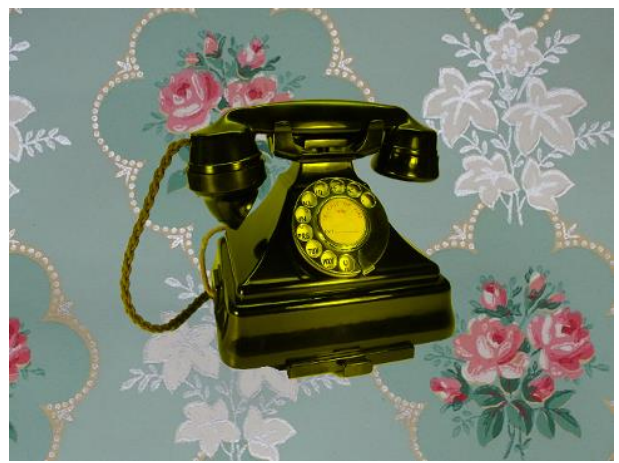

Figure 4: Artefact concept example

In terms of building physical prototypes instruction was given in the Arduino toolkit (Arduino 2016) a popular microcontroller-based board that can be used tethered to a PC by USB connector or as a standalone device. The application of these technologies was chosen for the course to give the possibility of making a working prototype through a series of versions. A low-fidelity prototype might be easily constructed from Arduino boards with added passive components as sensors. Sensors or actuators can be added by wiring individual passive components or by using a plug and play kit such as the Seeeduino Grove Starter kit (2016) that also includes an LCD display as seen in Figure 5 below. This early prototype (figure 5 . below) is the student's first attempt to incorporate these interactive devices into an object and shows promise. It relates to a concept to engage a young child with a code-breaking/communication challenge based on Morse code.

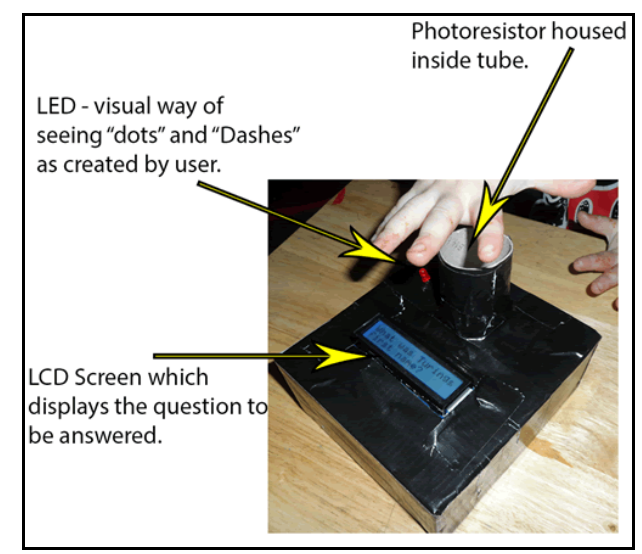

Figure 5: First prototype (Student C)

The benefit of these hardware toolkits is that they allow a rapid lo-fidelity prototype to be made quickly, and also for quick iteration. The prototype would be developed and then later presented to the museum education team for feedback,

Applying the User Experience Design method of user personas to further refine the design process allowed the students to imagine how the device would be used. The persona method attributed to a 
visitor to the museum, and often as in the case below to a specific age group. The kind of persona modelling is not common in the games development process, which tends to be rather focussed on the gameplay and technology only. However, as cited in the research above the user experience is essential in the development of interactive products for the museum scenario. We also felt that the area of 'narrative' could be improved in our student groups, as they are computing students rather than specialised in arts or media and typically are concerned with the technical or mechanics of development. However as the narrative element of gaming is a strong focus of commercial genres such as role playing and open worlds, the context of the museum experience also helps to support this narrative development and Bletchley Park in particular as a situated narrative in this case - the place where it actually happened.

As an example from the process a persona 'Robert' was developed by a student based on the interview findings of some museum visits, and a narrative developed to explain Robert's perceived interaction with the park. As this is a very useful and effective technique in interaction design (Preece et al. 2015), students have been encouraged to use these techniques to aid in the design process of their prototypes:

"Robert is an 11 year old boy who has lived in Milton Keynes his whole life. He lives with his mother, father and older brother. He is home schooled and has little interest in technology, preferring art and creative pursuits to computers. ....

Robert and his mother arrive at Bletchley Park and are informed about the "Code challenge" application ...

...Once out of the main building Robert hears his device "ping" and vibrates, alerting him to the presence of one of the parks interactive code breaking exhibits. Robert taps the beacon button on the application and looks for a flashing LED, as per the instructions he read earlier, to locate the device.

Robert and his mother enthusiastically search for the device, finally finding it inside a 1930's style telephone. Robert lifts the receiver and the LED stops flashing. However he cannot find instructions as to what to do next. His mother notices a glow from under the telephone and finds a small drawer. Robert pulls the drawer out and finds an LCD screen.

The $L C D$ screen presents them with a question and tells them to tap the answer out, in Morse code, on the telephones hook switch. A Morse code alphabet is displayed next to the telephone. Robert and his mum tap an answer in and receive a "correct" answer. They are then asked if they would like another question. Robert selects yes, and answers 3 more questions. He gets two right and one wrong, but tells his mother it was fun and wants to find the other devices." (Student C)

This narrative scenario outlines the more situated experience, and does well to put the playful interaction at the heart of the museum visit.

At the time of writing this particular group of students are working on individual projects including the audio or telephone-based device as described above, a motorbike handlebar controlled game and a hybrid radio-alarm clock that tells a historic timeline instead of the news. It is challenging to work with these materials in a limited amount of time, but the indication is that the combination of the context of the briefing, the toolkits and the possibility for the historically enchanted objects has potential.

\section{EVALUATION}

To understand how effective the Bletchley Park project is in enhancing learning and teaching, a questionnaire-based evaluation was carried out. The questionnaire was sent to the 30 students. 22 responses were received.

The key questions are as follows:

Q1. Have you had a similar learning experience before? - This question aims to find out the students' experience so that we have a better understanding on how the project is organised to compliment the student past experiences.

Q2. How satisfied you are with the project? - This questions aims to find out the student overall opinion to the project.

Q3. Any comments that you may have to your experience and suggestions to improve the project in the future? - This question is to get feedback from students for future improvement.

The following are the evaluation results and discussions:

Figure 6. shows that majority of the students did not have similar learning experience before, which means that the students are used to classroom based learning and not familiar with the types of learning that involved the external party. This is a good outcome because this enables student to have a clear comparison between the work-based learning experience and the classroom-based learning experience. 


\section{I had similar learning experience as the Bletchley Park project before}

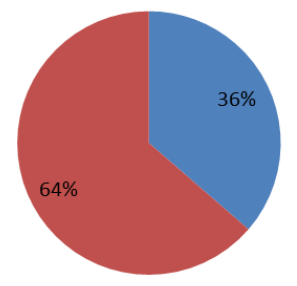

Figure 6. Percentage of the answers to $Q 1$

Figure 7 shows that $91 \%$ of the students are either satisfied or very satisfied with the project, which is a very good result. This is very encouraging for the project team to continue working on the project.

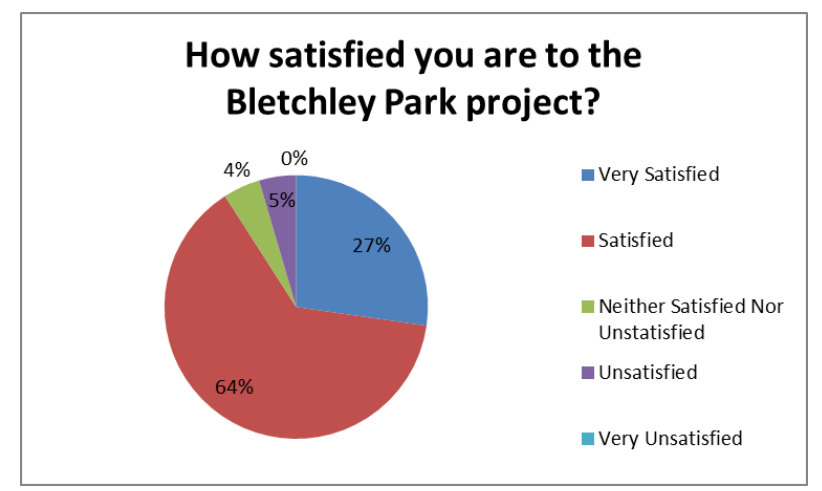

Figure 7. Percentage of the answers to Q2

The answers to the Q3 provide more valuable feedback for the future improvement of the project. In summary, the students think the project helps them to learn by applying their knowledge and skills to the real life scenario. They have learnt how to design a technology to meet the client's requirement. For example, "I think it is a really good idea to introduce a live project with the learning scheme. Not only was I able to design a present a mobile app, I was also able to learn how to handle live projects and situations."; "It is good because it gives the students a guideline for the projects, but still leave a great variety of options in design projects. It helps to contextualise the material from the lectures."

The students also think that the project motivated and helped them to learn about the history and Bletchley Park. For example, "It's good to know Bletchley Park."; "I have visited the park numerous times on my own as I enjoy learning about the place so much."; "We got to know a lot about Bletchley Park and its history through this project and I'm sure people who play it will be intrigued to find out more about Bletchley Park"
The students consider that this project improves their employability skills. For example, "I have learned to think outside the box."; "It's a great thing to put on the CV and come out above many other applicants"; "Working with a client and receiving feedback on the project has been a huge bonus." The overall good and bad about the project in the students' view: "It's a way to engage the visitors of Bletchley park more and spark their interest in Bletchley Park as a whole. In my opinion the interactive software or games are also one of the best ways to engage younger audience into Bletchley Park history"; "I believe it would be beneficial to try another project when time allows, although I would say financial support from the client would be valuable in terms of motivation for the projects as the development is a challenging and lengthy task."; "Definitely learned some good aspects and also bad habits of project management".

Overall, the pilot project has been successful so far in terms of student engagement, student experience and student employability. However, there is still capacity for improvement. Furthermore, the students who want to realise their prototypes to a production-level version may require financial support. Also as typical with group-work enhanced support should be provided to improve students' project management skills.

\section{CONCLUSIONS AND FUTURE WORK}

This paper presented a teaching and learning project carried out between the university teaching team and the museum education department. The project aims to teach technologies and techniques through history and enable students to apply the knowledge learnt through gaming. Some examples from the project have shown the potential of computer games and interactive projects to enhance the learning programmes of cultural heritage institutions. It has highlighted the combination of the use of skills from computer game development, to encourage gameful experiences that are also related to learning objectives. It also shows the benefits to students developing their skills in game design to have a situated context - a live brief - to enhance their learning experience. Together the result combines in a beneficial outcome.

From the education department perspective the team felt that developing relationships with organisations such as universities is potentially both an interesting and useful thing for us to do, allowing us to provide inspiration and context for students as they work towards various qualifications. In return, we will hopefully benefit 
from the creativity, insight and enthusiasm of these students and their innovations.

Given the generally positive response from participants it would be beneficial to continue the collaboration. To extend this it may be necessary to formalise the relationship between the parties involved and raise the typical questions about funding and resources. However the quite informal relationship that has been maintained through the previous years also has its benefits.

Other avenues for collaboration may include producing specific topic related learning materials, having situated displays within the site and collaborating on future plans for new interactives.

\section{ACKNOWLEDGEMENTS}

We acknowledge the work of the students involved in the project, particularly the originators of the selected prototypes given as examples: Student Group A: Khola Haroon, Zhijuan Yan; Student Group B: David Kaminski, Robert Billings, Philip Jones, Peter Wilsher, Katie Roach; Student C: J. Griffiths. Also Kate Travers, Head of Education, and other colleagues at Bletchley Park.

\section{REFERENCES}

Arduino (n.d.), [online] Available at: http://www.arduino.cc [Accessed 5 April 2016].

BBC (2016) Bang Goes The Theory [online]

Available at:

http://www.bbc.co.uk/programmes/b00lwxj1

[Accessed 5 April 2016].

Bergström, K., Waern, A., Rosqvist, D., and Månsson, L. (2014) Gaming in the crucible of science: gamifying the science center visit. In Proceedings of the 11th Conference on Advances in Computer Entertainment Technology, November (p. 2). ACM.

Bletchley Park. (2016) [online]

Bletchleypark.org.uk. Available at:

http://www.bletchleypark.org.uk [Accessed 5 April 2016].

Bletchley Park. (2016) Growth in Visitor Numbers.

[online] Available at:

https://www.bletchleypark.org.uk/content/about/

[Accessed 5 April 2016].

Bletchley Park. (2016) Learning Resources [online] Available at:

https://www.bletchleypark.org.uk/resources/filer.rht m/911902/pdf+for+workshop+information+primary. pdf [Accessed 5 April 2016].
Department of Computing, University of Bedfordshire (2016) Available at: http://www.beds.ac.uk/howtoapply/departments/co mputing [Accessed 5 April 2016].

Deterding, S., Dixon, D., Khaled, R., and Nacke, L. (2011) From game design elements to gamefulness: defining gamification. In Proceedings of the 15th International Academic MindTrek Conference: Envisioning Future Media Environments, September (pp. 9-15). ACM.

DJ Willrich (2016) [online] Available at: http://www.djwillrich.com/bletchley-park [Accessed 5 April 2016].

Event Communications (2016) [online] Available at: http://www.eventcomm.com/work/bletchley-parknational-codes-centre\#.VwLqyHDbBAw [Accessed 5 April 2016].

Eureka! (2016) [online] Available at: https://www.eureka.org.uk [Accessed 5 April 2016].

Keene, S. (2014) Museums and the Digital: The View from the Micro Gallery. In Proceedings of the EVA London 2014 on Electronic Visualisation and the Arts (pp. 114-121). BCS.

Liu, H. and Wood, J. (2014) Developing a pedagogical framework to involve external partners in teaching and curriculum development. University of Bedfordshire Conference, June.

Marshall, P. (2007) Do tangible interfaces enhance learning? In Proceedings of the 1st international conference on Tangible and Embedded Interaction, February (pp. 163-170). ACM.

Preece, J., Sharp, H., and Rogers, Y. (2015) Interaction Design: Beyond Human-Computer Interaction, 4th edition, Wiley.

Rose, D. (2014) Enchanted Objects: Design, Human Desire, and the Internet of Things. Simon and Schuster.

Seeeduino Grove Starter Kit (2016) [online]

Available at:

http://www.seeedstudio.com/wiki/Grove Starter Kit [Accessed 5 April 2016].

The Science Museum (2016) [online] Available at: www.sciencemuseum.org.uk [Accessed 5 April 2016].

Stevenson, J. (1987) The philosophy behind launch pad. Journal of Education in Museums, 8, pp.1820.

Uckelmann, D., Harrison, M., and Michahelles, F. (2011) An architectural approach towards the future Internet of Things (pp. 1-24). Springer, Berlin/Heidelberg. 